\title{
Fibrous Pseudo tumor of Right Testis \& Hydrocele of Left Testis - - A case report
}

\author{
Uma Tayal $^{1}$, Malay Bajpai, ${ }^{2}$ Ankit Jain ${ }^{3}$, Khalda $^{4}$, Aditi $^{5}$ \\ ${ }^{I}$ Associate Professor, Pathology Rama medical college,Hospital \& research center[RMCH\&RC] Ghaziabad \\ ${ }^{2}$ Associate Professor, Pathology Rama medical College, Hospital \& research centre Ghaziabad \\ ${ }^{3}$ Assistant Professor, Pathology [RMCH\&RC] Ghaziabad \\ ${ }^{4}$ Assistant Professor, Dept. of Pathology [RMCH\&RC] Ghaziabad \\ ${ }^{5}$ Assistant Professor , Dept. of Pathology [RMCH\&RC] Ghaziabad
}

\begin{abstract}
Pseudotumour or tumor like proliferation (non-neoplastic mass) are rare in testis and paratesticular structures. Clinically these lesions are of great intrest for the reason as they minimic as a malignancy arising from scrotal sac.[1,2] which result in treatment, often by radical orchidectomy. Their incidence among tumors arising with in scrotal sac varies according to different series from 6-30\% [2].Although fibrous pseudo tumour of testis affects patients of all ages, highest incidence is in third decade of ife.Therefore it is an important diagnostic consideration in young patients presenting with painless scrotal swelling.

Here we report a rare case of fibrous Pseudotumour of right testis \& left hydrocele. The purpose of this case report is to emphasis that how the practicing surgeons and pathologist may distinguish pseudotumours, the benign mimickers, from the true neoplasm so that surgeons can preserve the testis at least in some of the cases.
\end{abstract}

Key Words: Fibrous Pseudo tumor, intrascrotal mass, hydrocele testis.

\section{Case Report}

38 year old male patient was admitted in Rama Medical College Hospital \& Research Centre with the complain of firm swelling in Right scrotal region \& cystic swelling in left side scrotum. Left side swelling is larger then right side.

History of trauma 10 years back was given. No history of significant weight loss was given \& appetite was normal. Physical examination revealed an irregular, firm, nontender mass in right scrotum that did not transilluminate, lymph node were not palpable. Left side scrotum swelling was found to be hydrocele.

Abdominal examination was normal and lymph nodes were not palpable.Routine pre operative investigations were normal.

USG:

Scrotal ultrasound demonstrate a complex lesion that encased the testicle in right scrotum.

In view of clinical suspicion of testicular malignancy, a right high inguinal orchidectomy was performed.

Histopathological finding: GROSS-Received two specimen, labelled A, right testis tumour mass AND $B$,part of left hydrocele sac.

Specimen A) :-Consist of an oval tumor like mass that measured $9 \times 6 \times 4.5 \mathrm{~cm}$ with attached spermatic cord that measures $5.5 \mathrm{~cm}$ in length. The tumor like mass is firm to hard, grayish white.[Fig no.1]

Specimen B) : - Flat, grey white membranous tissue piece measuring $1.5 \times 1.0 \times 0.3 \mathrm{~cm}$.

CUT SECTION: Specimen A) : - Testis was surrounded by the tumor like mass . The testicular parenchyma was unremarkable grossly \& was encased in the tumor mass and measures $3.5 \times 2 \mathrm{~cm}$. Rest of the mass is solid fibrotic, firm and pale yellow.

\section{Microscopic Examination}

Multiple $\mathrm{H} / \mathrm{E}$ stained section from fibrous mass shows a paucicellular lesion composed of dense fibrocollagenous stroma containing chronic inflammatory infiltrate, myofibroblast \& thickened blood vessels. In some foci the inflammatory infiltrate was sparse where as in the other areas of the lesion the inflammation was more pronounced \&composed of small lymphoid aggregates . Necrosis, mitotic activity, cellular pleomorphism were absent. Section from testis showed diminished spermatogenesis.Tumour mass was well demarcated from the testis by fibrous tissue. Extensive examination 
did not revealed any features of malignancy.[Fig.no.2,3]Rete testis \& spermatic cord including vasdefernce were normal.

Section from left hydrocele sac showed fibrous tissue lining, and few inflammatory cells, hemorrhagic areas, increased number of blood vessels. These features are consistent with hydrocele sac.

The diagnosis was made histopathologically but to reconfirm and for research purpose immunohistochemistry for vimentin and smooth muscle was done and the tumor showed positivity for both of them.With these finding, diagnosis of Fibrous Pseudo Tumor right testis with hydrocele left side was given.

\section{Discussion}

Para testicular fibrous pseudo tumor is an uncommon entity, recognized first in 1904 by Balloch [3] Although rare it is the second most common benign Paratesticular lesion after adenomatoid tumor [4,5]. The tumor has a peak incidence in third decade of life but can occur at any age. These lesion may be of varying size \& frequently present as a unilateral mass. Bilaterality is however rare. This patient presented with right Fibrous Pseudo Tumor of Testis and left side hydrocele, an unusual combination. Clinically the lesion mimic malignant process \& frequently present as painless palpable intrascrotal mass. Discomfort secondary to the lesion has been reported in case when the tumor involves tunica vaginalis, epidedymis \& spermatic cord.

Patient may give history of trauma, hydrocele or inflammation.[6] In present case patient had complained of scrotal trauma 10 years before the development of tumour. The tumour most commonly arises from Tunica vaginalis, with less then $15 \%$ arising from the tunica albugina \& spermatic cord. [7] In present case the tumor was arising from Tunica vaginalis.

Ultrasonographic appearance of tumor is widely variable with variable echogenicoty. Grossly tumor are typically hard grayish white, nodular as in present case.[ 8] microscopically tumor is often paucicellular, fibroblastic \& dense hylinezed collagen stroma with fibrblastic or mybofibroblastic activity chronic inflammatory, partially granulation tissue, calcification, myxoid changes or even ossification may be seen.[9]

Histologically differential diagnosis of this tumor includes :-

A ) :- Solitary fibrous tumor showing spindle cell in vague or pattern.

B ) :- Leiomyoma with smooth muscle cells in interlacing fascicles.

C ) :- Fibroma of tunica \& idiopathic fibromatosis with proliferating fibroblast in a bed of collagen.

The lesion can also be differentiated based on positive or negative infiltrative border [9].

\section{Conclusion}

In most case of Fibrous Pseudo para testicular tumor, patient undergo extensive surgery because of need to exclude malignancy. Incision biopsy in these cases may be contributory if the surgeon and pathologist are aware of this diagnosis and performance of radical orchidectomy may be prevented at least in some of the cases.

References
[1]. F. Algaba
1,2, G. Mikuz ${ }_{\mathrm{ET}}^{3}$ AL, Pseudoneoplastic lesions of the testis and paratesticular structures Virchows Arch. Dec 2007; 451(6): 987-997.

[2]. Haas GP, Shumaker BP, Cerny JC (1986) The high incidente of benign testicular tumors. J Urol 136:1219-1220

[3]. Parker PM, Pugliese JM, Allen RC Jr. Benign fibrous pseudotumor of tunica vaginalis testis. Urology 2006; 68: 427.e 17-9.

[4]. Mostofi FK, Price EB. Tumors of the male Genital System. Atlas of Tumor Pathology, 2ndseries, fascicle 8. Washington DC: Armed Force Institute of Pathology; 1973: 151-4.

[5]. Oliva F, Young RH. Paratesticular tumor-like lesions. SeminDiag Pathol2000; 17: 358.

[6]. Srigley JR, Hartwick RWJ. Tumors and cysts of the paratesticular region.Pathol Annu1990; 25: 51-108.

[7]. Gogus O, Bulay O, Yurdakul T, Beduk Y. A rare scrotal mass:Fibrous pseudotumor of epididymis. Urol Int'1 1990; 45: 63-4.

[8]. Beccia DJ, Krane RJ, Olsson CA. Clinical manangement of non-testicular intrascrotal tumors J Urol 1976; 116: 476-9.

[9]. Seethala RR, Tirkes TA, Weinstein S et al. Diffuse fibrous pseudotumor of the testicular tunics associated with an inflamed hydrocele. Arch Pathol Lab Med 2003; 127: 742-4. 